\title{
Design of Shallow p-type dopants in $\mathrm{ZnO}$
}

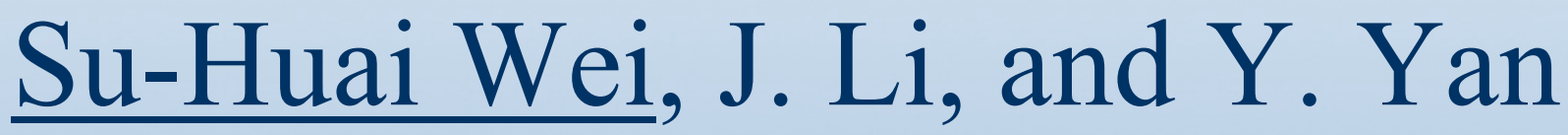

\section{National Renewable Energy Laboratory, U.S.A.}

NREL/PR-520-43248

Presented at the 33rd IEEE Photovoltaic Specialist Conference held May 11-16, 2008 in San Diego, California 


\section{The work at NREL is supported by the U.S. DOE under contract No. DE-AC36-99GO10337.}




\section{Introduction}

$>\mathrm{ZnO}$ is a promising material for short wave-length opto-electronic devices such as UV lasers and LEDs due to its large exciton binding energy and low material cost

$>\mathrm{ZnO}$ can be doped easily n-type, but the realization of stable p-type $\mathrm{ZnO}$ is rather difficult

Using first-principles band structure methods we will address:

$>$ What causes the p-type doping difficulty in $\mathrm{ZnO}$

$>$ How to overcome the p-type doping difficulty in $\mathrm{ZnO}$

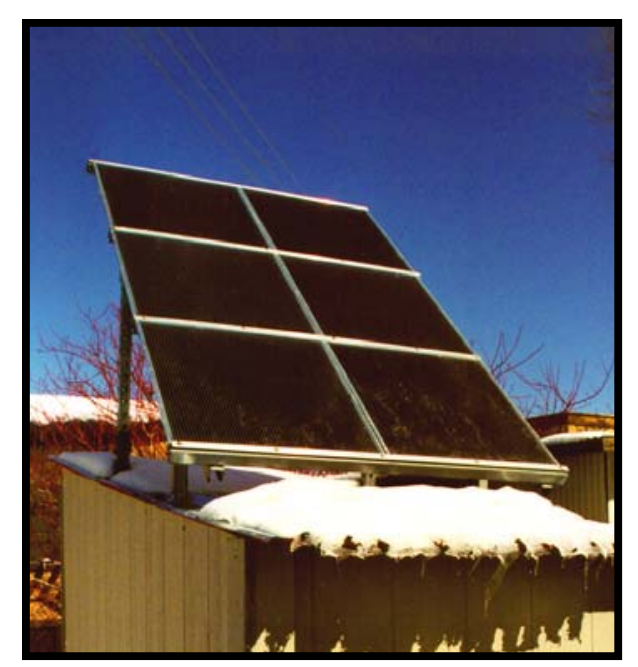




\section{Chemical Trends of Atomic Energy Levels}

Chemical trends of atomic energy levels

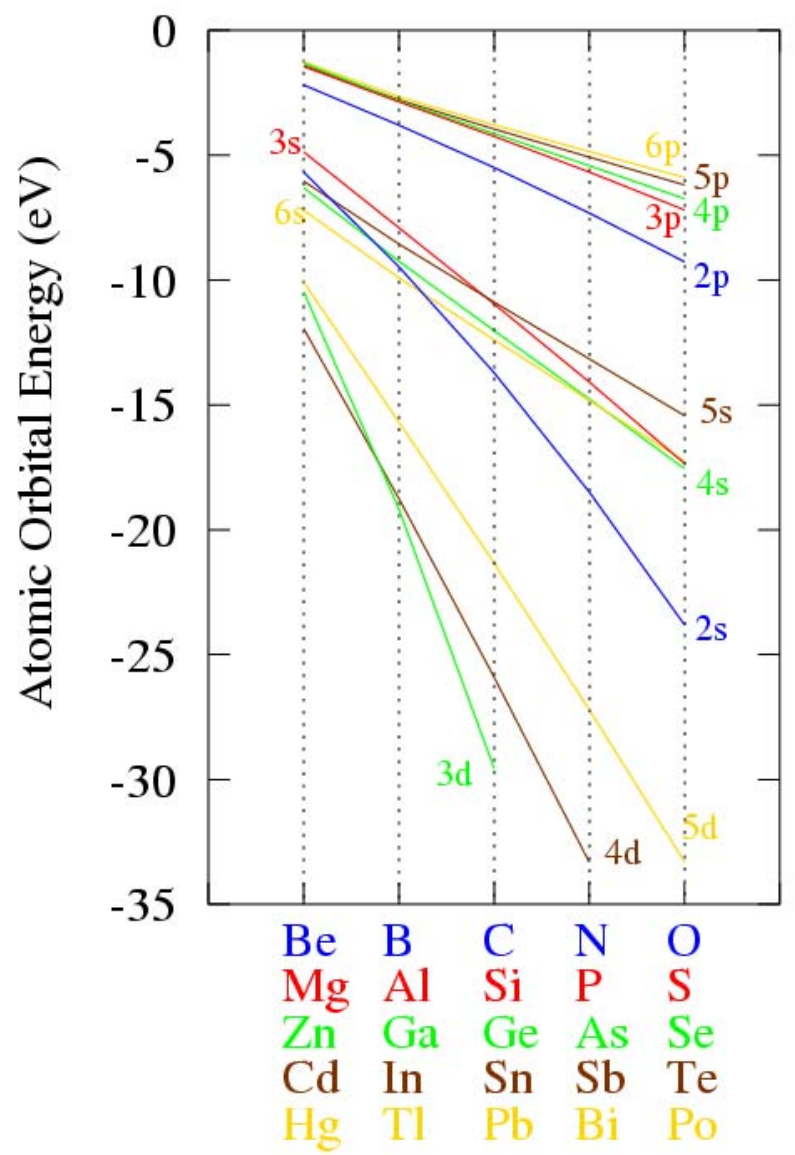

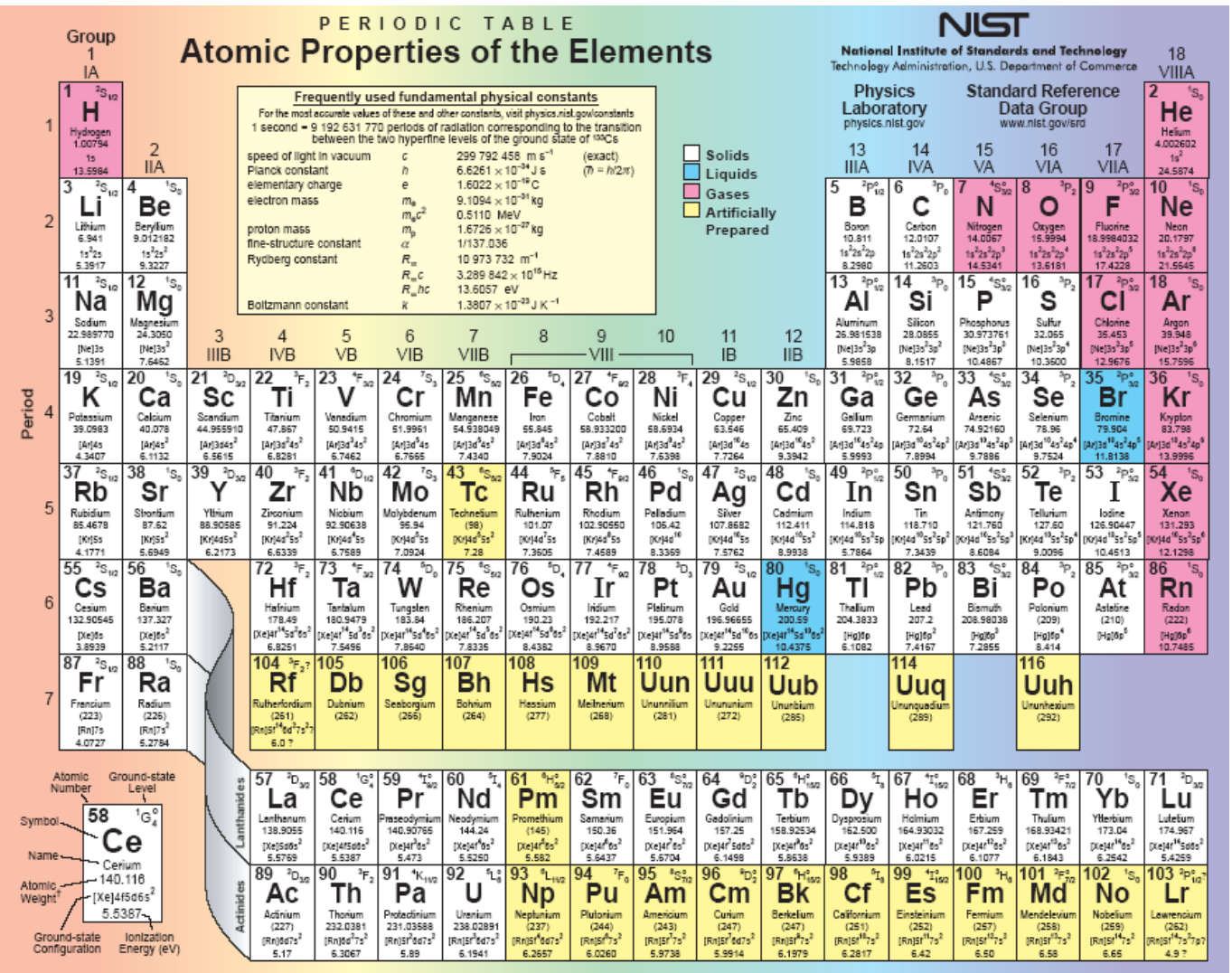

Atomic potential becomes more negative when the atomic number increases from left to right in the Periodic Table 


\section{Method of Calculation}




\section{Method of calculation}

- Band structure and total energy are calculated using the firstprinciples band structure method (FLAPW, PP) with local density approximation (LDA)

- Defects are described using the supercell approach. A uniform background charge is added for charged defect calculation

- All the internal structural parameters are optimized by minimizing the quantum mechanical forces

- Band in different supercell calculations are aligned using atomic core levels or average potentials 


\section{Origin of the p-type doping difficulty in $\mathrm{ZnO}$}




\section{Main reasons of failure-to-dope}

- The impurity atom has limited solubility in the host material, so not enough dopants are introduced

- The defect transition energy levels are too deep, so not enough charge carrier are generated at working temperature

- Spontaneous formation of opposite-charged "killer defects" (cation vacancy, anion vacancy, etc.), which pins the Fermi energy 
Origin of p-type doping difficulty in $\mathrm{ZnO}$ :

high acceptor formation energy

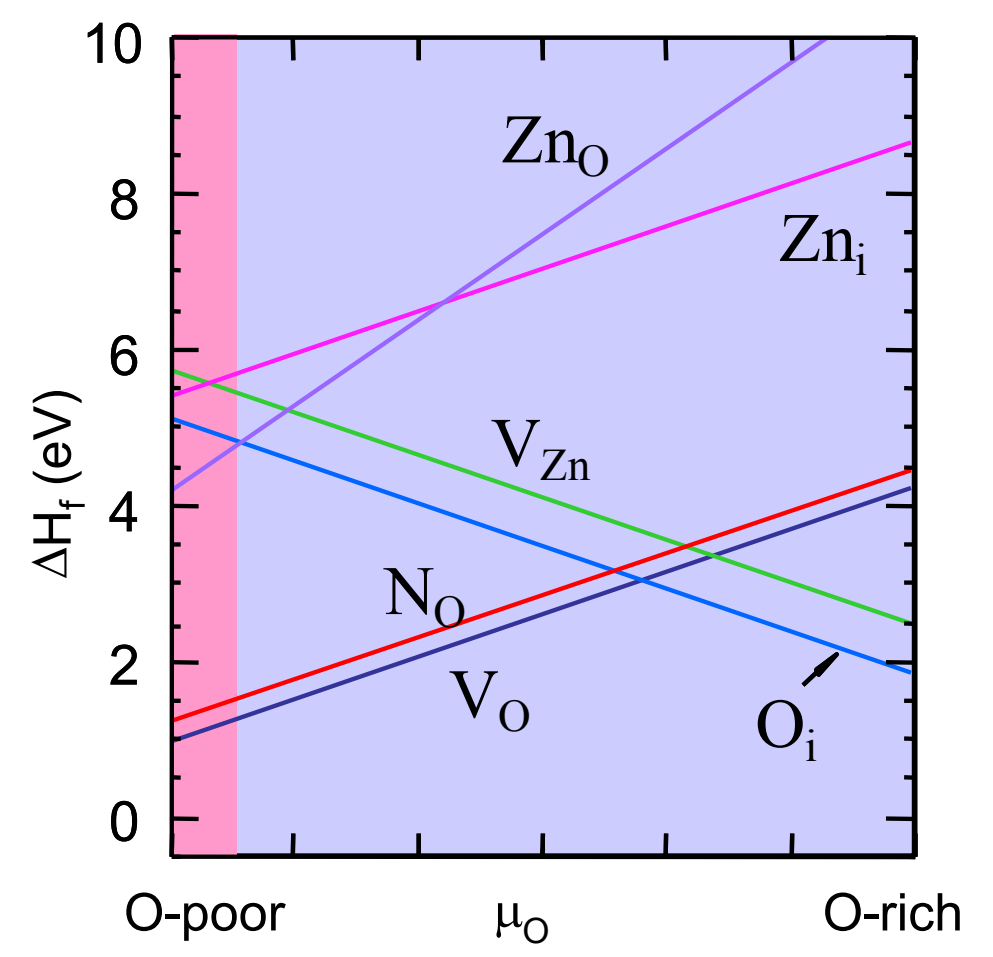

Due to the strong bonding and large formation energy of $\mathrm{ZnO}$, intrinsic defect formation energies are large

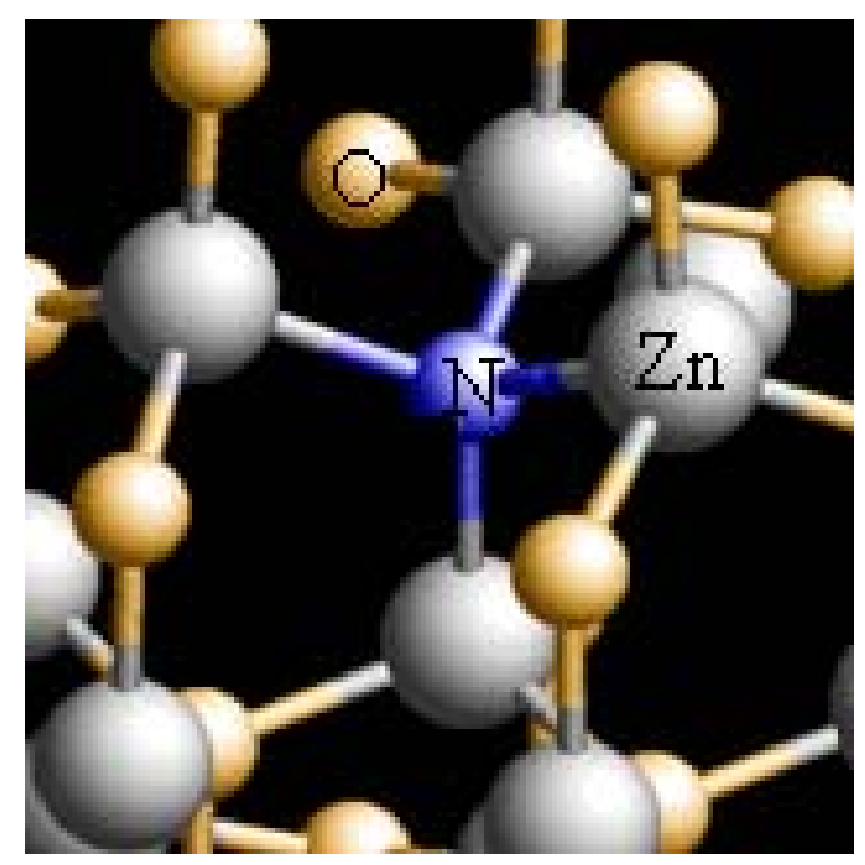

Calculate minimum defect formation energy of neutral $\mathrm{N}_{\mathrm{O}}$ $\mathrm{H}_{\mathrm{f}}\left(\mathrm{N}_{\mathrm{O}}\right)_{\min }=1.2 \mathrm{eV}$ 


\section{Origin of p-type doping difficulty in $\mathrm{ZnO}$ : high acceptor ionization energy}

\section{Acceptor energy levels in $\mathrm{ZnO}$}
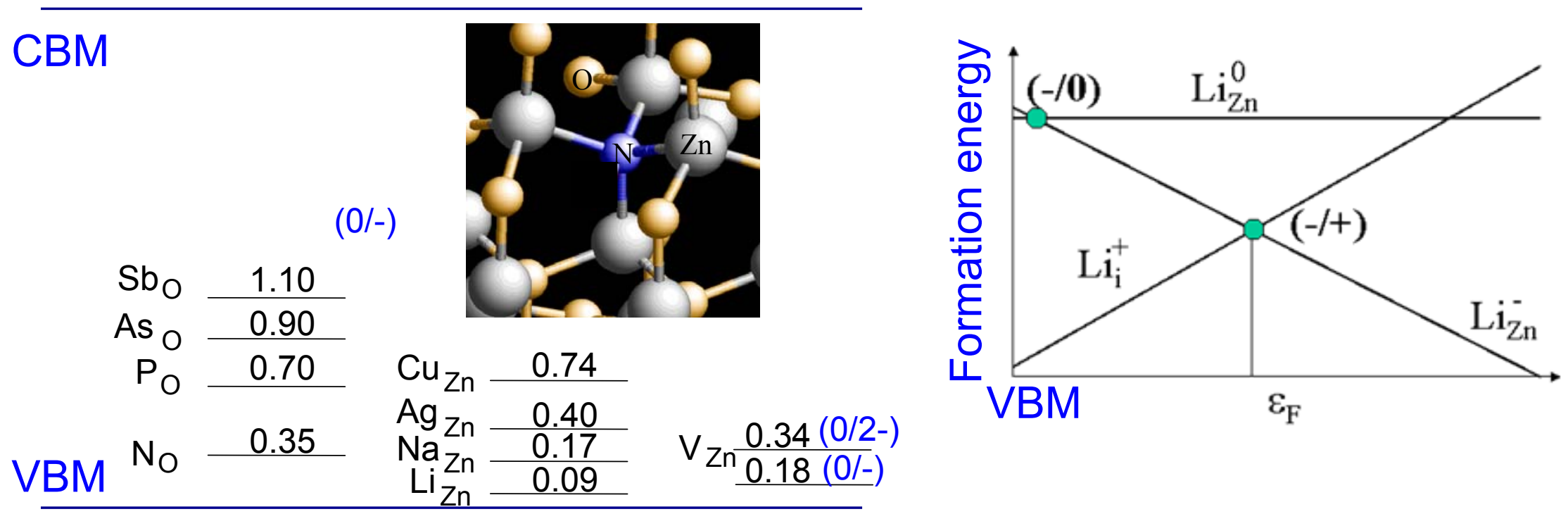

- For group $V$ on oxygen site acceptor, the lowest transition energy level $\mathrm{N}_{\mathrm{O}}$ is $0.35 \mathrm{eV}$ above the VBM

- For group IB on Zn site acceptor, the lowest transition energy level is also deep, at $0.40 \mathrm{eV}$ for $\mathrm{Ag}_{\mathrm{Zn}}$

- Group IA on Zn site has relatively shallow defect level, but self compensation limits their use as effective acceptor 


\section{Origin of p-type doping difficulty in $\mathrm{ZnO}$ : high acceptor ionization energy}

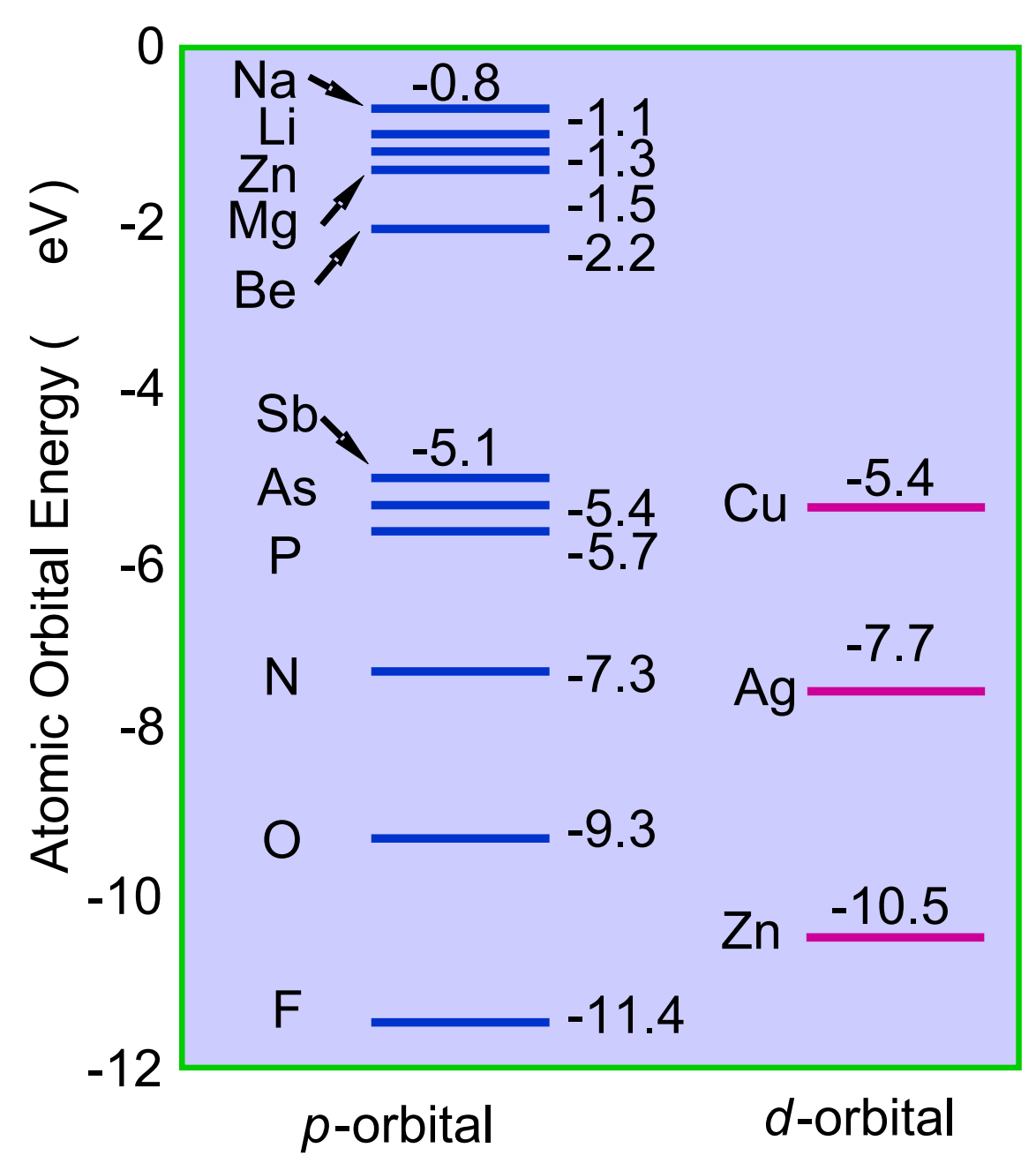

> An acceptor level above VBM has a wavefunction character similar to the VBM, i.e. it has an anion $p$ and cation $d$ orbital characters

$>$ Oxygen $p$ orbital energy is very low, there are no group- $\mathrm{V}$ elements that are more electronegative than $\mathrm{O}$

$>p$ - $d$ coupling between host elements and dopants (e.g., $\mathrm{N}_{\mathrm{O}}$ with $\mathrm{Zn}$ or $\mathrm{Cu}_{\mathrm{Zn}}$ with $\mathrm{O}$ ) is large 


\section{Strategies to overcome the doping limit}

> Increase defect solubility by "defeating" bulk defect thermodynamics

$>$ Reduce defect ionization level through proper codoping techniques

$>$ Reduce defect compensation and ionization level by modifying the band edge states 


\section{Improve the Dopant Solubility by Adjusting Dopant Chemical Potentials}




\section{Increase defect solubility using non-equilibrium thermodynamics}

$>$ What controls the dopant solubility is the dopant chemical potential, $\mu_{\mathrm{A}}$. Therefore, the key to enhance the solubility of the dopant is to raise the chemical potential and avoid the formation of the precipitates of the dopants

$$
\Delta H^{(\alpha, q)}\left(E_{F}, \mu\right)=\Delta E^{(\alpha, q)}\left(E_{F}=0, \mu_{i}=0\right)+\sum n_{i} \mu_{i}+q E_{F}
$$

$>$ Choose the optimal host element chemical potentials

$>$ Enhance solubility by metastable molecular doping

$>$ Enhance solubility by epi-growth (e.g., MBE) 


\section{Choose the optimal host element chemical potentials}

- The formation energy of $\mathrm{N}_{\mathrm{O}}$ is the lowest under O-poor condition, whereas $V_{Z n}$ is the lowest under the O-rich condition

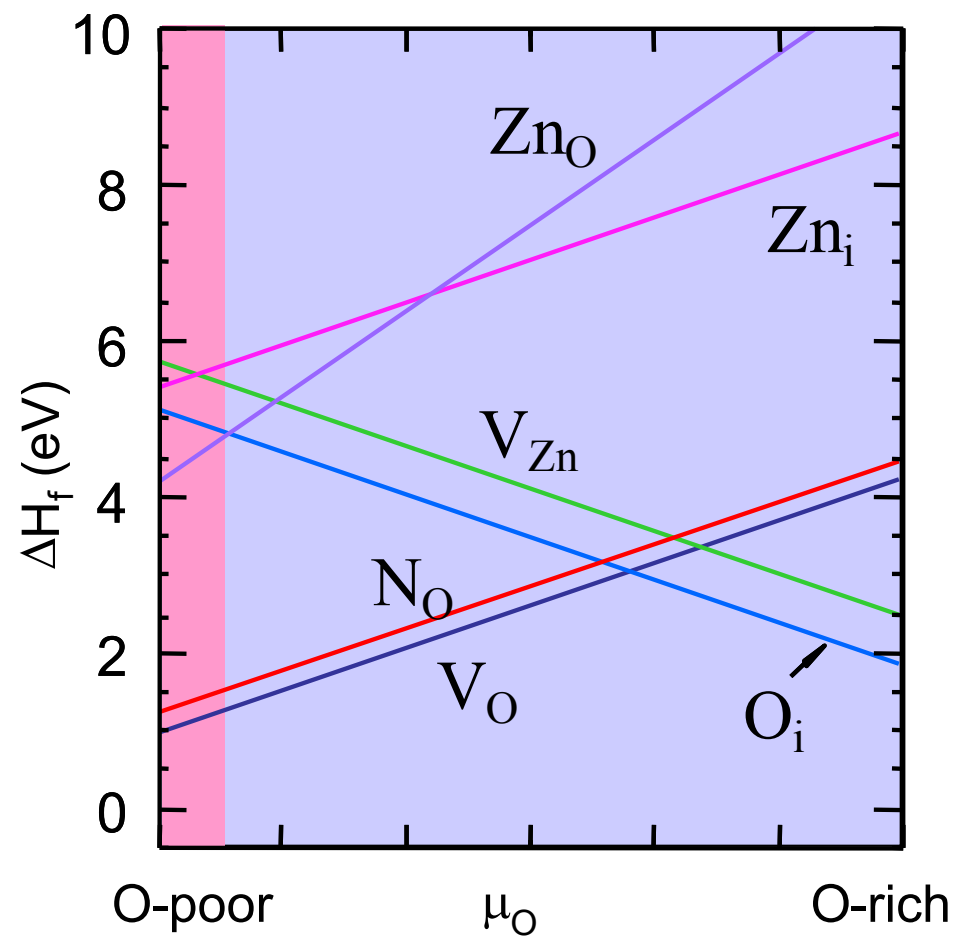

$$
\begin{gathered}
\Delta \mathrm{H}_{\mathrm{f}}=\mathrm{E}(\mathrm{ZnO}: \mathrm{N})-\mathrm{E}(\mathrm{ZnO})+\mu_{\mathrm{O}}-\mu_{\mathrm{N}} \\
\Delta \mathrm{H}_{\mathrm{f}}=\mathrm{E}\left(\mathrm{ZnO}: \mathrm{V}_{\mathrm{Zn}}\right)-\mathrm{E}(\mathrm{ZnO})+\mu_{\mathrm{Zn}}
\end{gathered}
$$




\section{Enhanced solubility by molecular doping: $\mathrm{ZnO}: \mathrm{N}$}

$$
\begin{gathered}
\Delta H_{f}=E(Z n O: N)-E(Z n O)+\mu_{O}-\mu_{N} \\
\Delta H_{f}=E(Z n O: N)-E(Z n O)+2 \mu_{O}-\mu_{N O} \\
\mu_{N}\left(N_{2}\right)<\mu_{N}\left(N_{2} O\right)<\mu_{N}(N O)<\mu_{N}\left(N_{2}\right)
\end{gathered}
$$

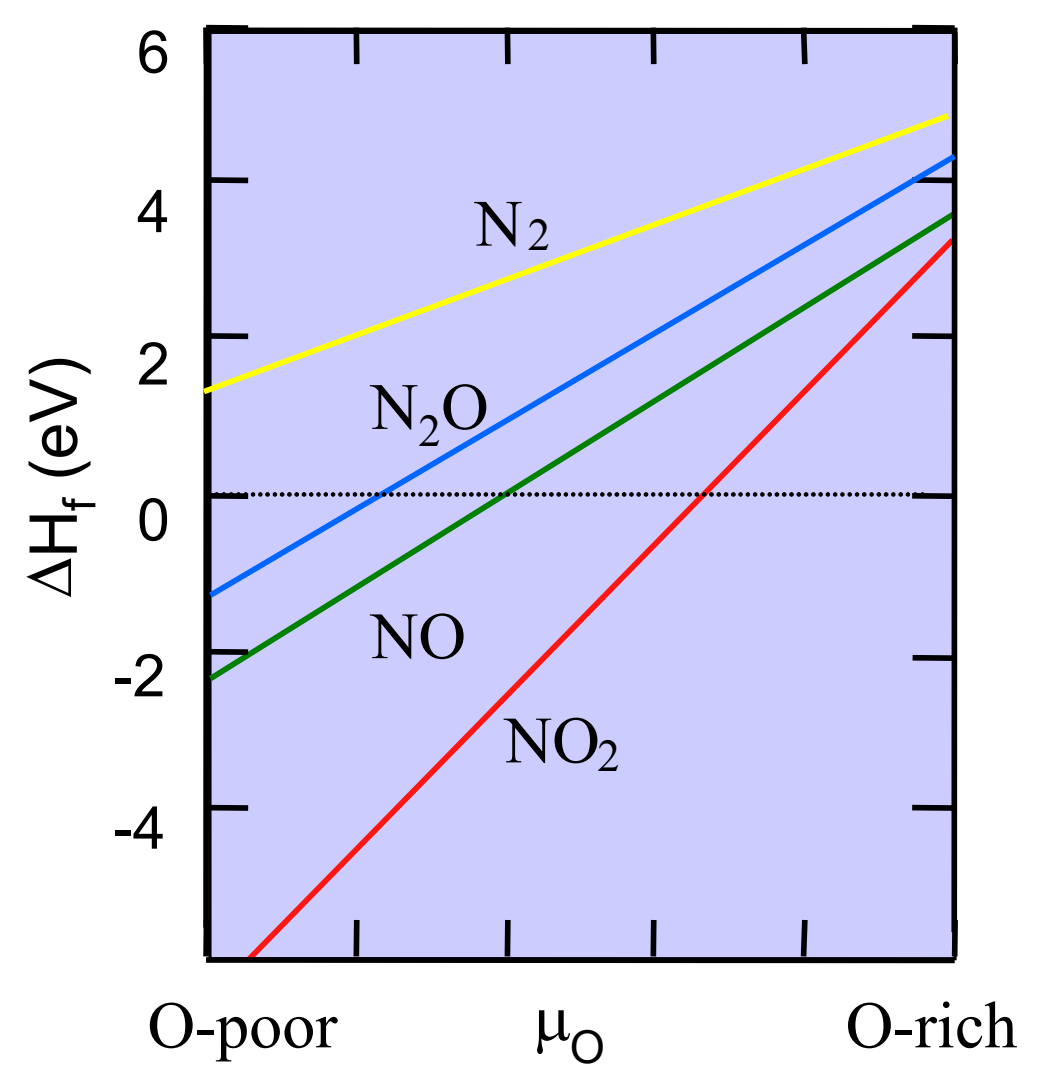

$\mathrm{N}$ chemical potential depends on the doping sources $\left(\mathrm{N}_{2}, \mathrm{~N}_{2} \mathrm{O}, \mathrm{NO}, \mathrm{NO}_{2}\right)$

$\mathrm{N}$ solubility in $\mathrm{ZnO}$ is much higher if $\mathrm{NO}$ or $\mathrm{NO}_{2}$ is used as dopant

$\mathrm{NO}$ or $\mathrm{NO}_{2}$ doping also avoids the formation of $\left(\mathrm{N}_{2}\right)_{\mathrm{O}}$, which is a compensation donor in $\mathrm{ZnO}$ 


\section{Single $\mathbf{N}$ atom in $\mathrm{ZnO}$}

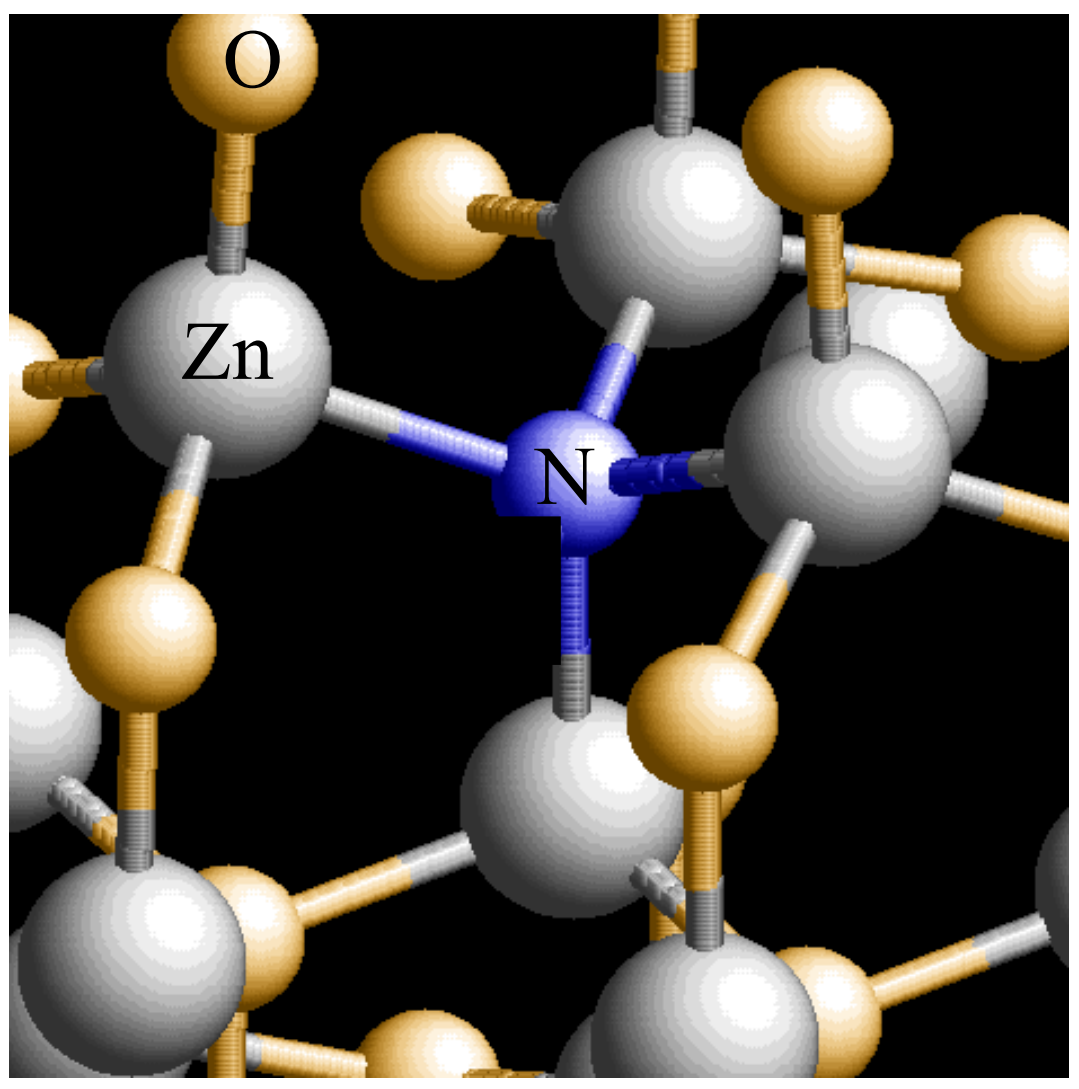

Transition energy level of $\mathrm{N}_{\mathrm{O}}$

$E(0 /-)=V B M+0.35 \mathrm{eV}$

Calculate minimum defect formation energy $\mathrm{N}_{\mathrm{O}}$

$\mathrm{H}_{\mathrm{f}}\left(\mathrm{N}_{\mathrm{O}}\right)_{\min }=1.2 \mathrm{eV}$

$\mathrm{H}_{\mathrm{f}}\left(\mathrm{N}_{\mathrm{O}}\right)_{\text {min }}=0.4 \mathrm{eV} \quad\left(\mathrm{NO}, \mathrm{Zn}_{3} \mathrm{~N}_{2}\right)$ 
Design shallow defect levels in $\mathrm{ZnO}$ using band structure calculation method 


\section{Effects of conventional co-doping}

- Can co-doping lower the defect transition energy levels?

$$
v_{z n}+G a_{z n}
$$

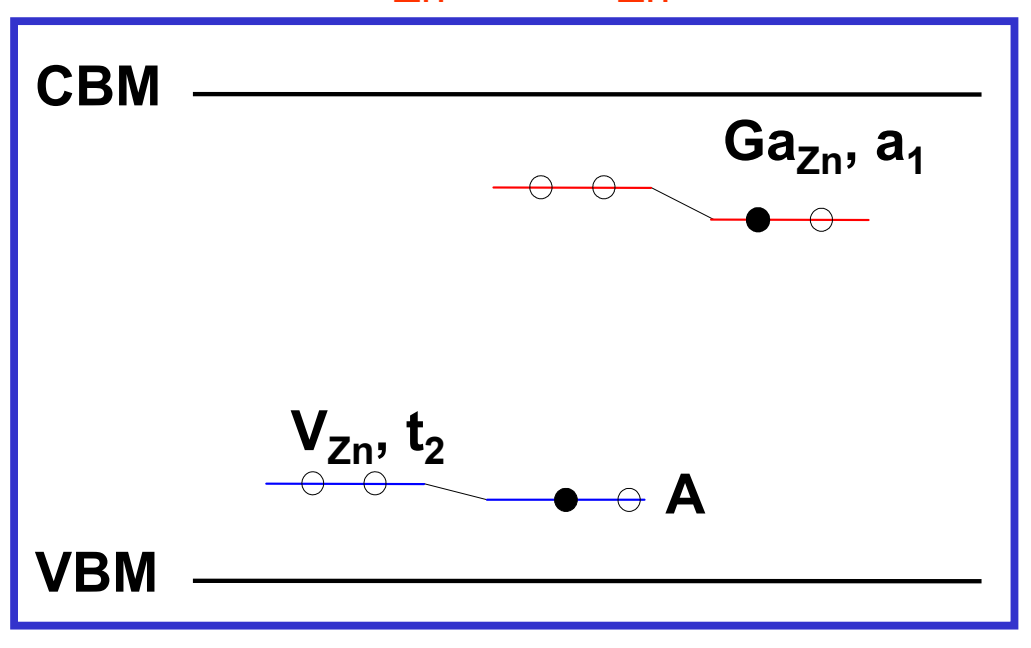

$$
2 \mathrm{~N}_{\mathrm{O}}+\mathrm{Ga}_{\mathrm{Zn}}
$$

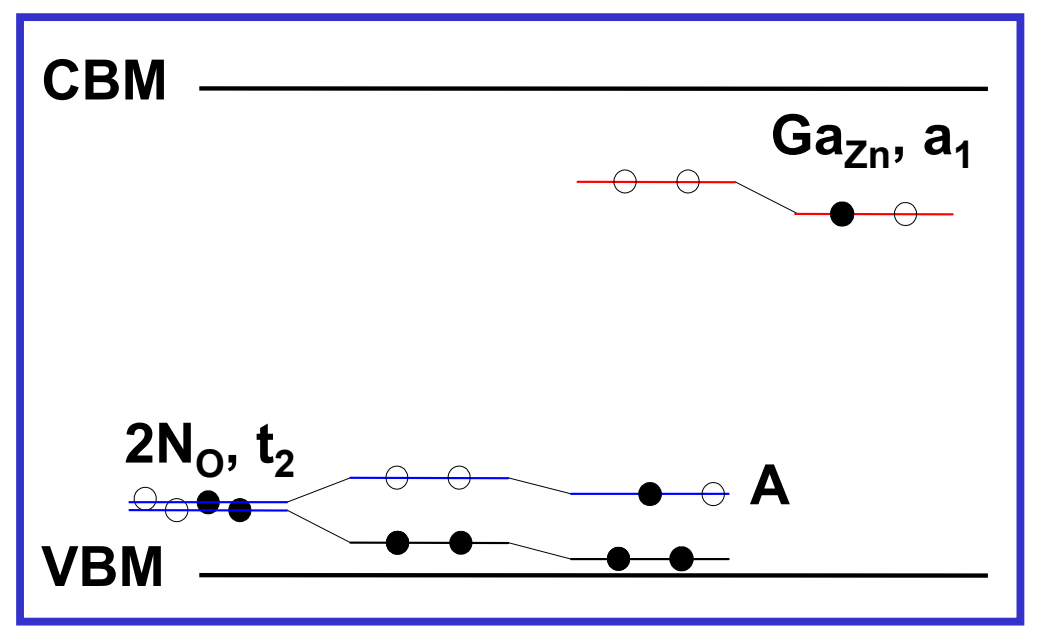

$>$ The level repulsion effect is rather small because the donor state and the acceptor states have different symmetry

$>$ The defect transition energy level may be lowered only if the defect complex consists a single donor and a single acceptor 


\section{Design shallow p-type dopants in $\mathrm{ZnO}$}

(a) $\mathrm{V}_{\mathrm{Zn}}$

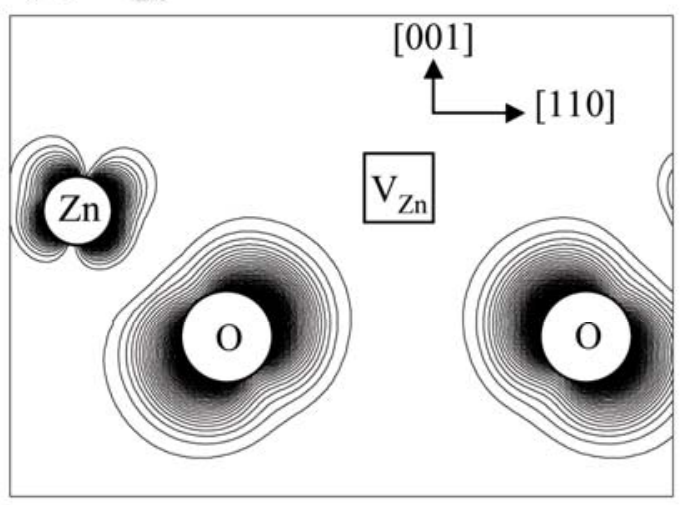

(c) $\mathrm{N}_{\mathrm{O}}$
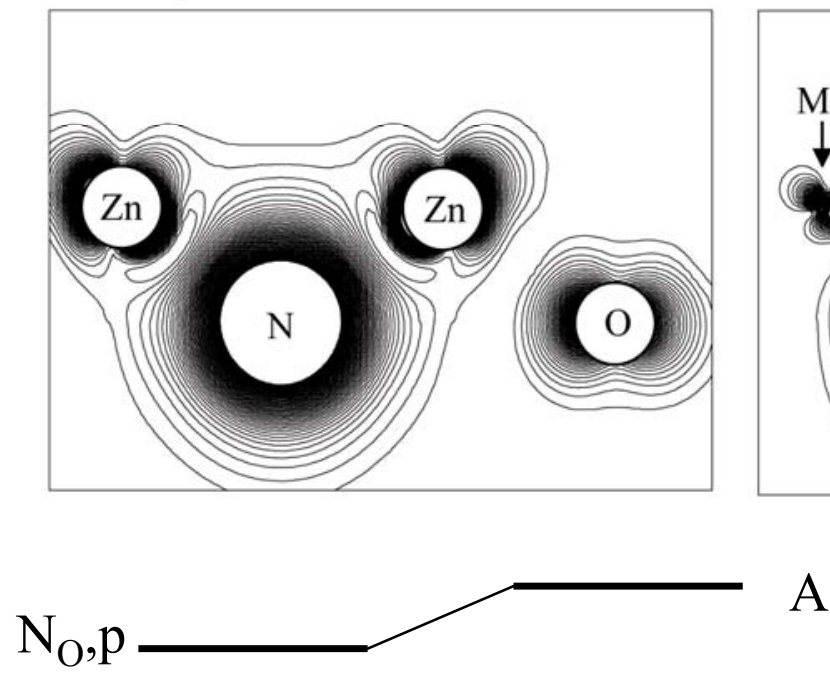

$\mathrm{Zn}, \mathrm{d}$ (b) $\mathrm{V}_{\mathrm{Zn}}+\mathrm{F}$

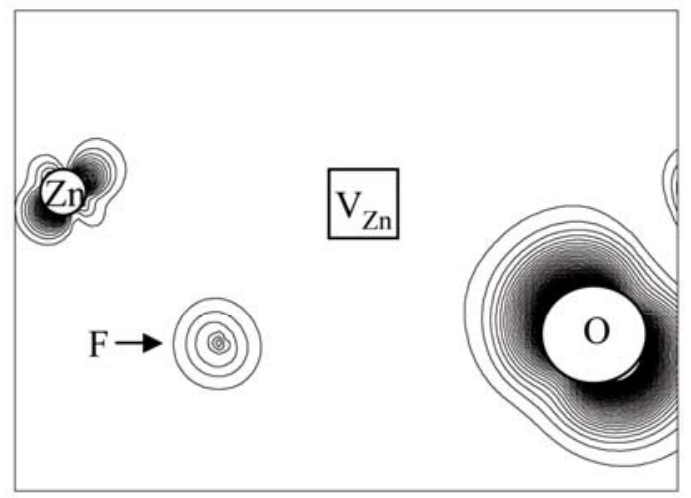

(d) $4 \mathrm{Mg}+\mathrm{N}_{\mathrm{O}}$

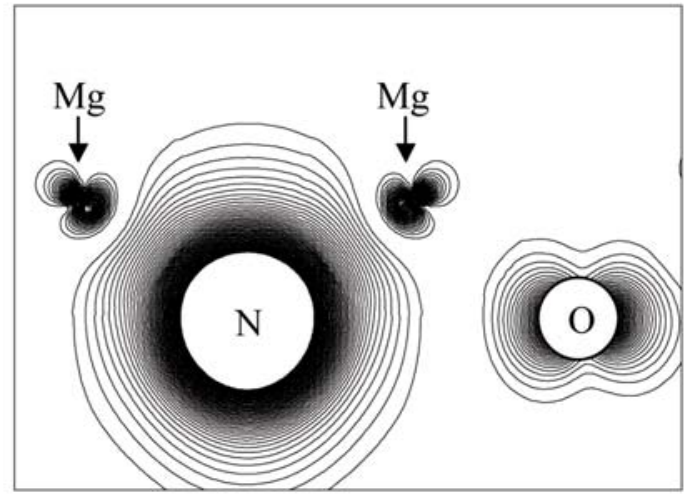

A

$\mathrm{Zn}, \mathrm{d}$
$>$ Defect wavefunction has large weight on its neighboring atoms

$>$ Replace $\mathrm{O}$ by the more electronegative $\mathrm{F}$ is expected to lower $\mathrm{V}_{\mathrm{Zn}}$ energy level

$>$ Remove $\mathrm{p}-\mathrm{d}$ coupling between $\mathrm{N}_{\mathrm{O}}$ and cation by replacing $\mathrm{Zn}$ with $\mathrm{Mg}$ or $\mathrm{Be}$ is also expected to reduce the acceptor energy level 


\section{Design shallow p-type dopants in $\mathrm{ZnO}$}

\begin{tabular}{cccc}
\hline \hline Defect & $\mathrm{E}_{b}$ & $(0 /-)$ & $(-/ 2-)$ \\
\hline $\mathrm{N}_{O}$ & & 0.31 & - \\
$\mathrm{N}_{O}-\mathrm{Mg}_{Z n}$ & 0.3 & 0.29 & - \\
$\mathrm{N}_{O}-4 \mathrm{Mg}_{Z n}$ & 1.6 & 0.23 & - \\
$\mathrm{N}_{O}-\mathrm{Be}_{Z n}$ & 0.1 & 0.22 & - \\
$\mathrm{N}_{O}-4 \mathrm{Be}_{Z n}$ & 1.9 & 0.12 & 0.34 \\
$\mathrm{~V}_{Z n}$ & & 0.18 & - \\
$\mathrm{V}_{Z n}-\mathrm{F}_{O}$ & -2.3 & 0.16 & \\
\hline \hline
\end{tabular}

$>$ The calculated defect ionization energy levels suggest that $\mathrm{F}$ and $\mathrm{Be}$ could be good p-type co-dopant for $\mathrm{ZnO}$ 


\section{Reduce self-compensation by introducing Group-IB acceptors in $\mathrm{ZnO}$}
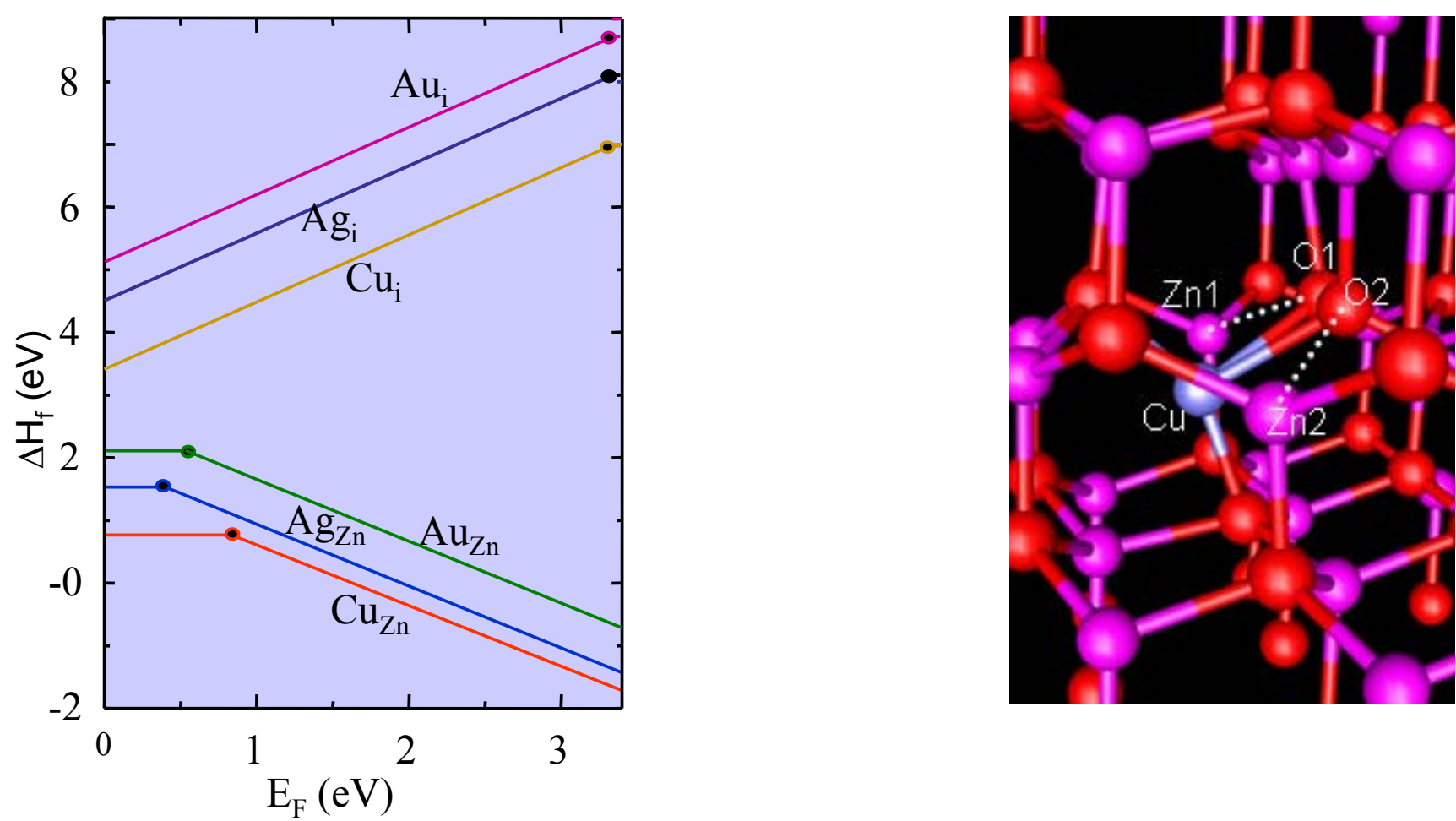

$>\mathrm{Cu}_{\mathrm{Zn}}$ has very deep acceptor level because of the large $\mathrm{p}-\mathrm{d}$ coupling, but $\mathrm{Ag} \mathrm{Zn}$ has relatively shallower levels

$>\mathrm{IB}_{\mathrm{i}}$ is highly unstable, so self-compensation for IB dopants is low 


\section{Large size mismatched p-type doping in $\mathrm{ZnO}$ :As}

\section{Background:}

p-type conductivity in As and P-doped $\mathrm{ZnO}$ have been observed and conventional doping model attributed the dopants to $\mathrm{As}_{\mathrm{O}}$ and $\mathrm{P}_{\mathrm{O}}$

$>$ We have show that $\mathrm{As}_{\mathrm{O}}$ and $\mathrm{P}_{\mathrm{O}}$ are unlikely to be the measured acceptor because

- The formation energy is high (As and $\mathrm{P}$ is much larger than $\mathrm{O}$ )

- The ionization energy of $\mathrm{As}_{\mathrm{O}}$ and $\mathrm{PO}$ are very high $\sim 0.8 \mathrm{eV}$

\section{Acceptor energy levels in $\mathrm{ZnO}$}

$$
\begin{array}{rr}
\mathrm{Sb}_{\mathrm{O}} & \multicolumn{1}{c}{1.10} \\
\mathrm{~s}_{\mathrm{O}} & 0.90 \\
\mathrm{P}_{\mathrm{O}} & 0.70 \\
\mathrm{~N}_{\mathrm{O}} & 0.40
\end{array}
$$




\section{Large size mismatched p-type doping in $\mathrm{ZnO}$ :As}

The new model:

- Atomic size of As and $\mathrm{Zn}$ are similar

- $\mathrm{As}_{\mathrm{Zn}}$ has relatively lower formation energy but it is a (triple) donor

- $\mathrm{V}_{\mathrm{Zn}}$ is a native (double) acceptor with low formation energy

- One $A s_{Z n}$ and two $V_{Z n}$ bind strongly and form a new acceptor complex $\left(\mathrm{As}_{\mathrm{Zn}}-2 \mathrm{~V}_{\mathrm{Zn}}\right)$

- The complex has low formation energy and low ionization energy $(\sim 150 \mathrm{meV})$

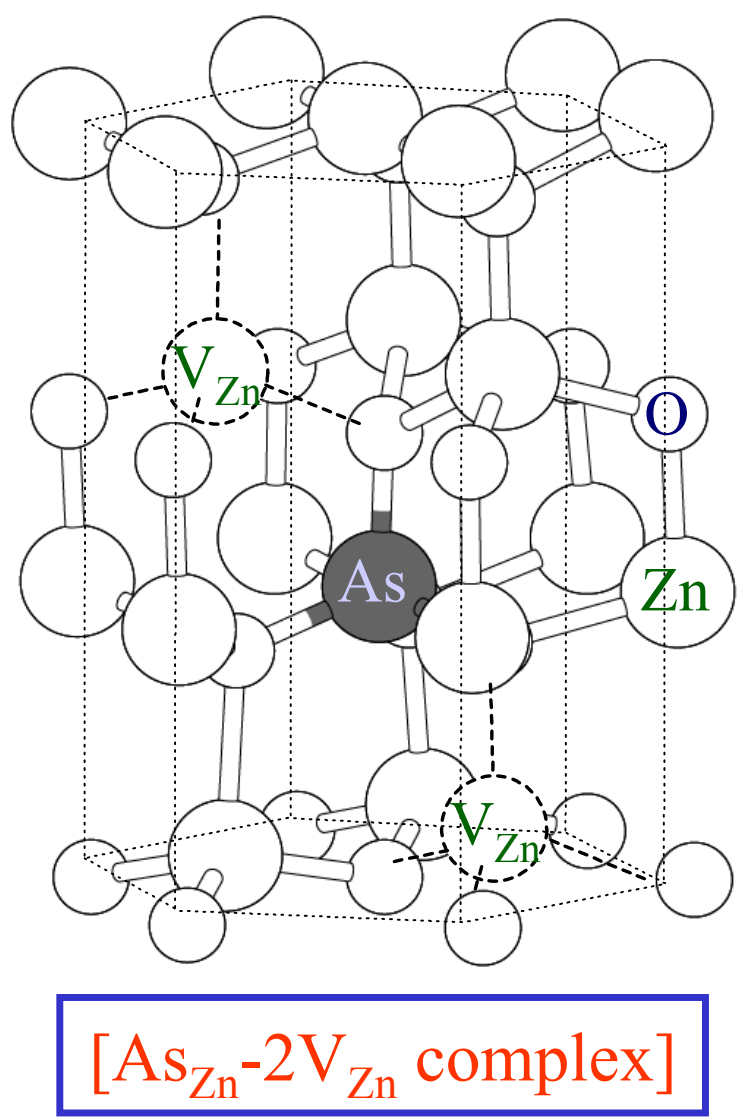




\section{Large size mismatched p-type doping in $\mathrm{ZnO}$ :As}

Calculated binding energy and defect formation energy for various As-related defect complexes in $\mathrm{ZnO}$

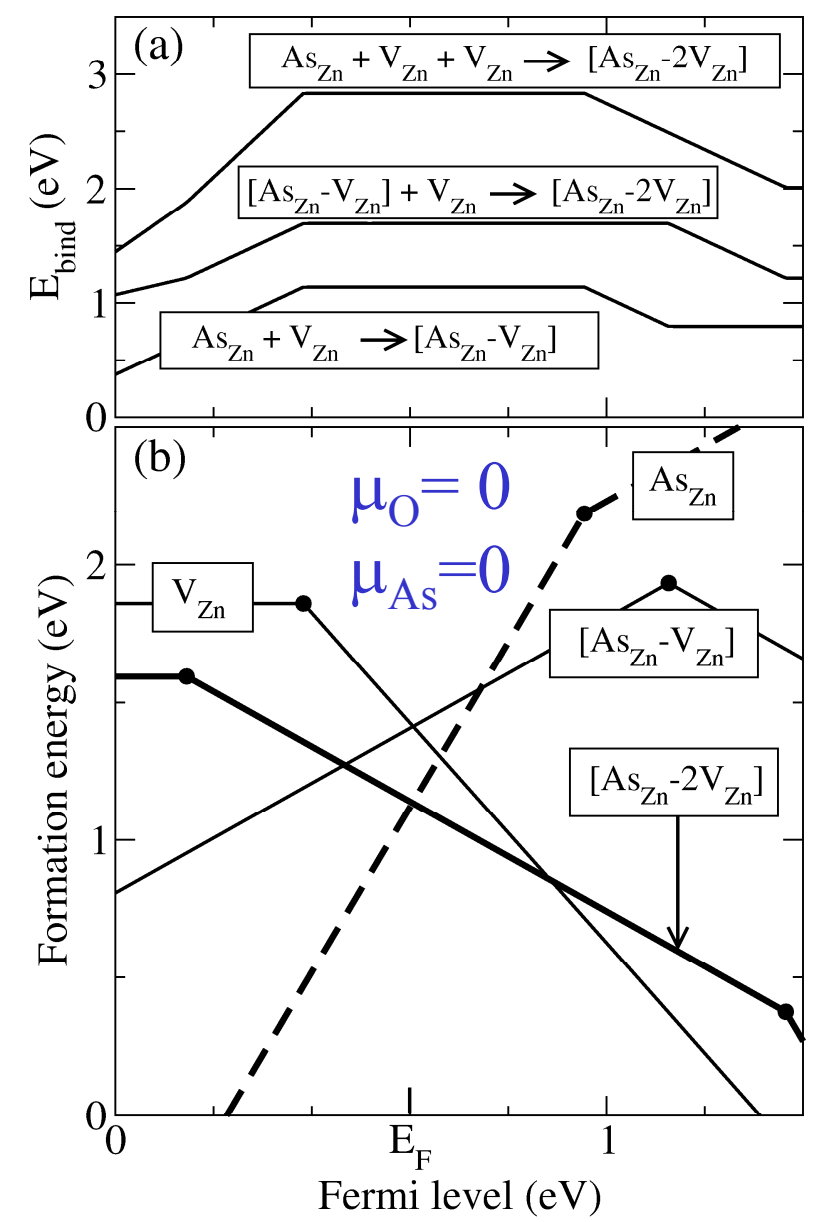

$>$ Strong Coulomb interaction and strain compensation lowers the formation energy of the $\mathrm{As}_{\mathrm{Zn}}-2 \mathrm{~V}_{\mathrm{Zn}}$ defect complex

$>$ Coupling between the $\mathrm{As}_{\mathrm{Zn}}$ donor states and the $\mathrm{V}_{\mathrm{Zn}}$ acceptor states lowers the ionization energy of the complex relative to $\mathrm{V}_{\mathrm{Zn}}$ 


\section{Modify the host band structure to} reduce ionization energy and compensation 


\section{Universal approach to overcome the doping asymmetry in wide-band-gap semiconductors}

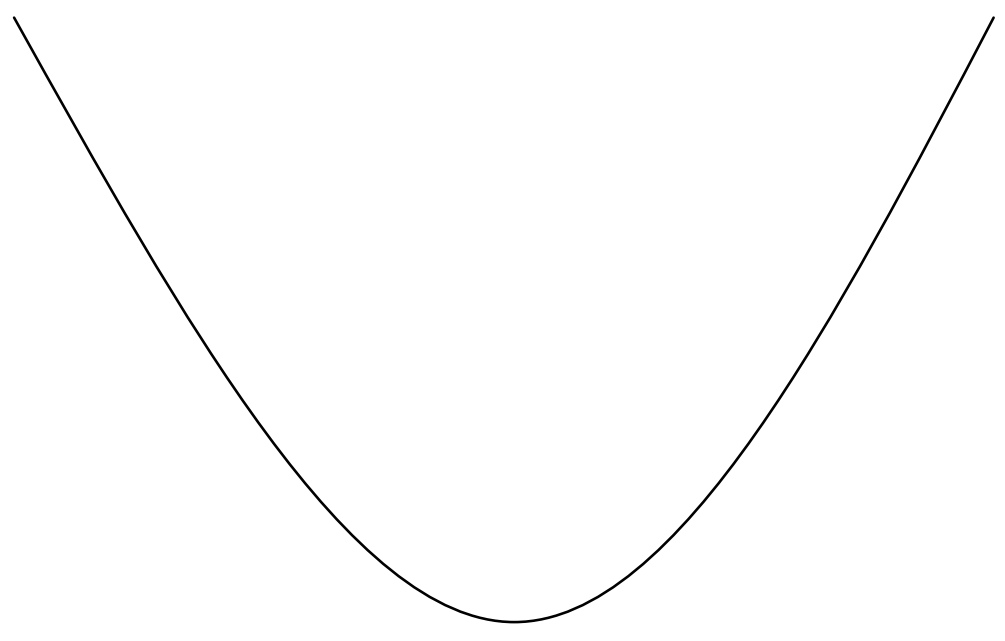

Excess dopant states

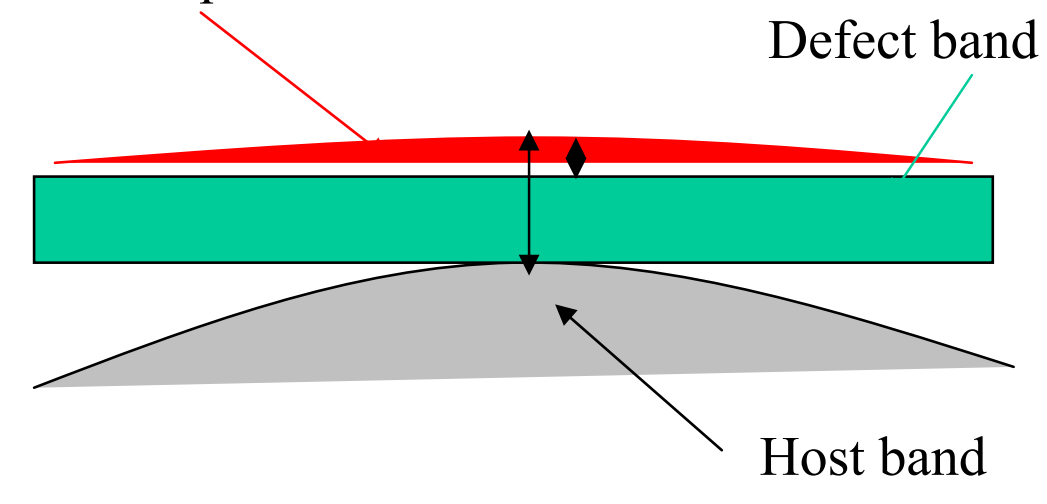

$>$ First, through effective doping of mutually passivated defect pairs, we introduce a fully compensated defect band near the VBM or CBM of the host

$>$ Second, after the fully compensated insulating phase is formed, use excess dopants to dope the passsivated system by ionizing the defect band 


\section{Modify the valence band edge of $\mathrm{ZnO}$ by passivate doping of $\mathrm{Ga}$ with $\mathrm{N}$}

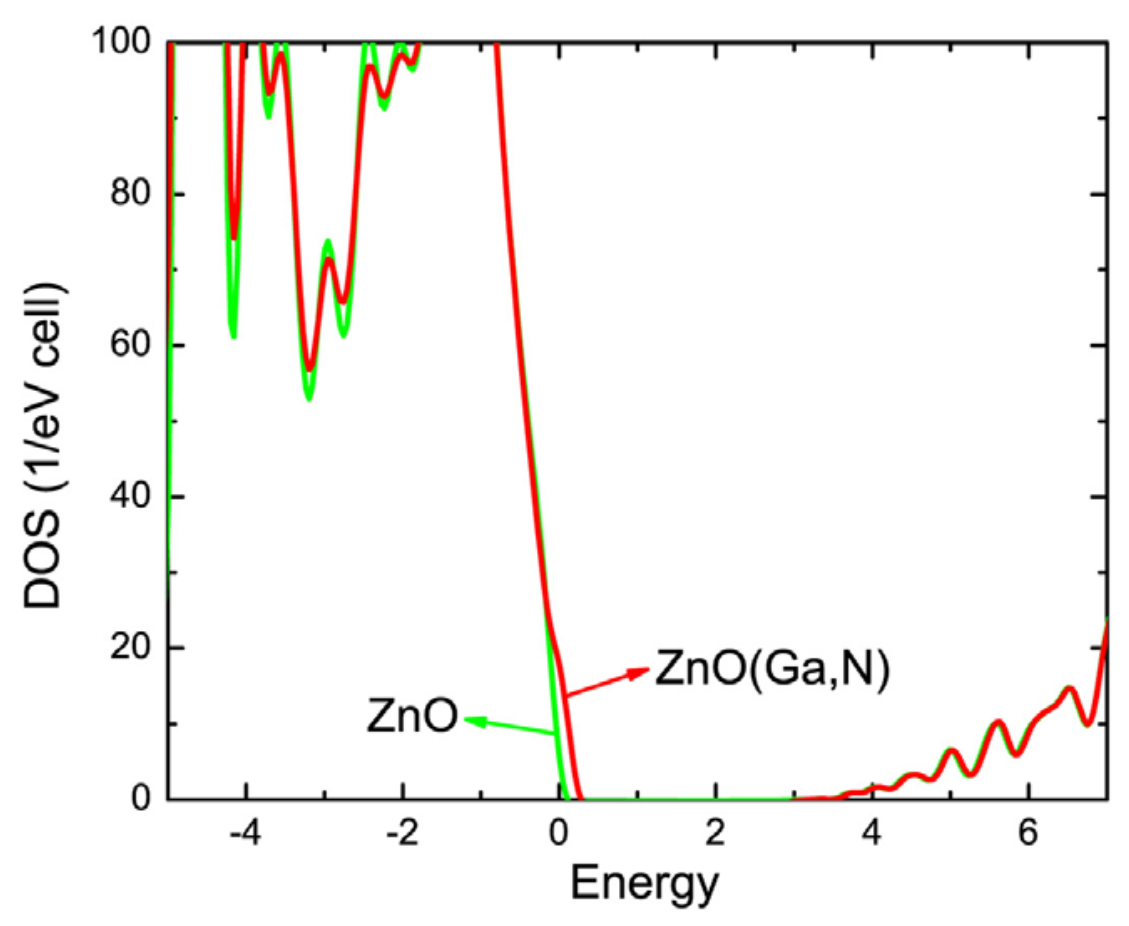

$>\mathrm{N}$ combined with Ga creates a passivated defect band above the host $\mathrm{ZnO}$ VBM 


\section{Create shallow acceptor level by doping the passivated $\mathrm{ZnO}:(\mathrm{Ga}+\mathrm{N})$ system using excess $\mathrm{N}$}

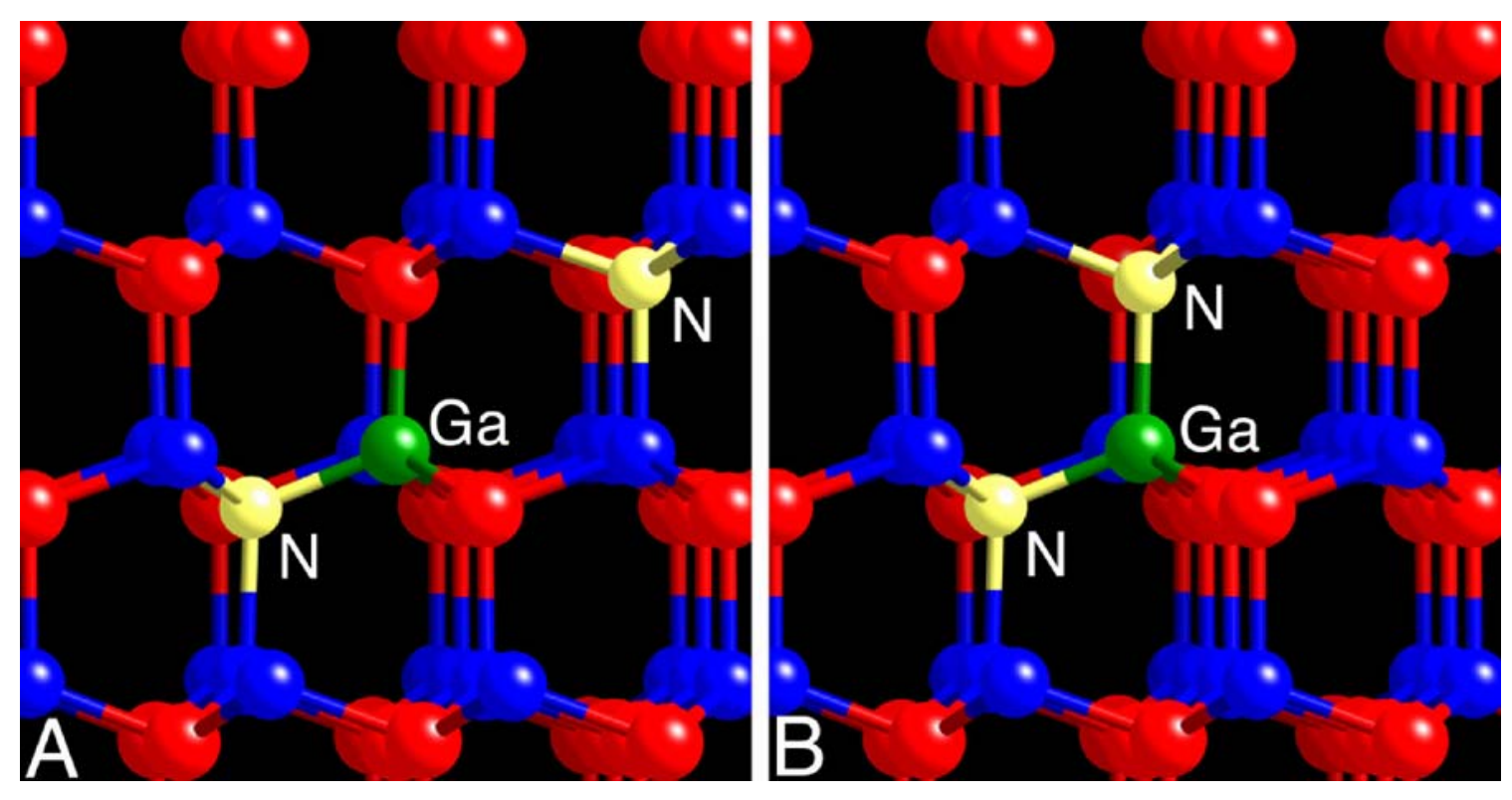

$>$ The calculated defect level of $\mathrm{N}$ is about $0.1-0.2 \mathrm{eV}$ above the defect band 


\section{Possible dopants or dopant complexes for}

\section{p-type doping in $\mathrm{ZnO}$}

$>$ Based on defect wavefunction analysis, various microscopic models have been proposed to reduce the ionization energy of acceptor level in $\mathrm{ZnO}$

$$
\begin{aligned}
& \mathrm{Ag}_{\mathrm{Zn}} ; \mathrm{V}_{\mathrm{Zn}}+\mathrm{F}_{\mathrm{O}} \\
& \mathrm{Mg}_{\mathrm{Zn}}+\mathrm{N}_{\mathrm{O}} ; \mathrm{Be}_{\mathrm{Zn}}+\mathrm{N}_{\mathrm{O}} \\
& \mathrm{As}_{\mathrm{Zn}}+2 \mathrm{~V}_{\mathrm{Zn}} ; \mathrm{P}_{\mathrm{Zn}}+2 \mathrm{~V}_{\mathrm{Zn}}
\end{aligned}
$$

$>$ Doping of defect band is an effective and universal approach to doped wide band gap materials such as $\mathrm{ZnO}$

$$
\mathrm{N}_{\mathrm{O}}+\left(\mathrm{N}_{\mathrm{O}}+\mathrm{Ga}_{\mathrm{Zn}}\right)_{\text {defect band }}
$$




\section{Summary}

We have analyzed the origin of p-type doping difficulty in $\mathrm{ZnO}$. Several strategies have been proposed to overcome the doping difficulty

- Increase defect solubility by "defeating" bulk defect thermodynamics using

- optimized host elements chemical potential

- surface enhanced defect solubility

- molecular doping

- large size-mismatched antisite doping

- Reduce defect ionization level by

- combining donor with acceptor to modify defect wavefunctions

- reducing p-d coupling between defect level and host states

- Design new dopable materials by adjusting the band edges states using passivated doping and subsequent doping using the same dopants 


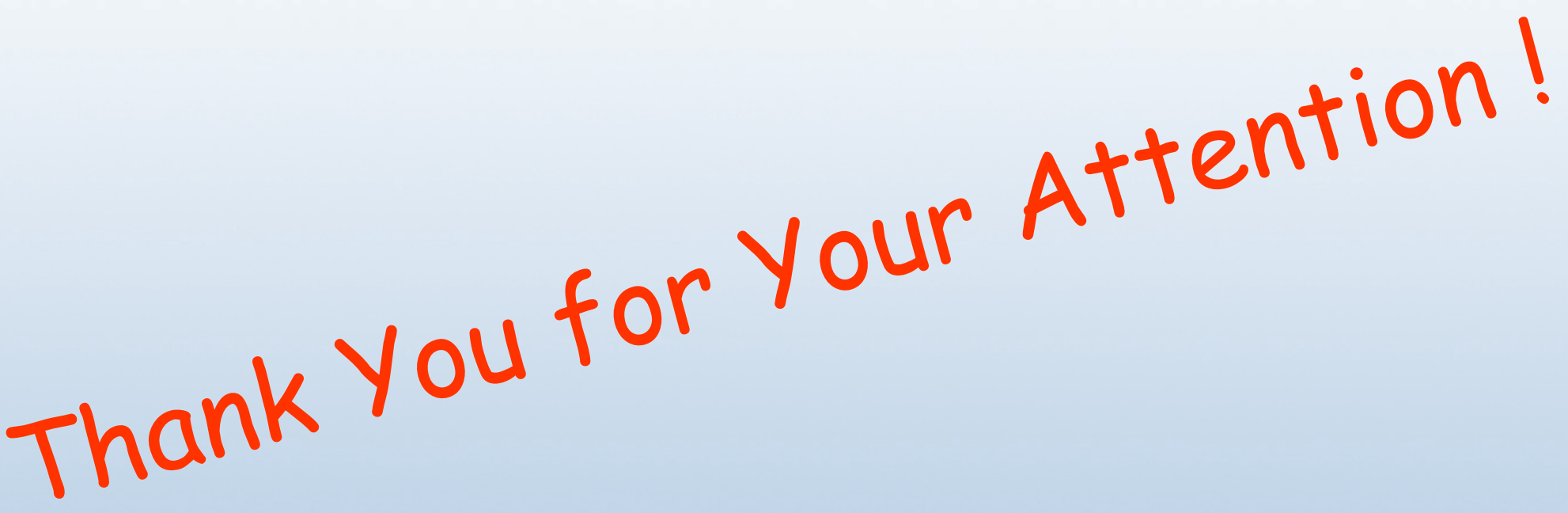

